\title{
Erratum to: The dynamics and mechanism of the antimicrobial activity of tea tree oil against bacteria and fungi
}

\author{
Wen-Ru Li ${ }^{1}$ - Hai-Ling $\mathrm{Li}^{1}$ • Qing-Shan Shi ${ }^{1}$ Ting-Li Sun ${ }^{1} \cdot{\mathrm{Xiao}-B a o ~ \mathrm{Xie}^{1}}^{1} \cdot \mathrm{Bin} \mathrm{Song}^{1}$ • \\ Xiao-Mo Huang ${ }^{1}$
}

Published online: 24 January 2017

(C) Springer-Verlag Berlin Heidelberg 2017

\section{Erratum to: Appl Microbiol Biotechnol \\ DOI 10.1007/s00253-016-7692-4}

Our paper entitled "The dynamics and mechanism of the antimicrobial activity of tea tree oil against bacteria and fungi" has been published on Applied Microbiology and Biotechnology (Vol. 100/Issue 20, pp 8865-8875). In this paper, many references relevant to researching of tea tree oil (TTO) have been cited for clarifying the development status of this research field. Unfortunately, we were not aware of Professor Gustafson's researching work during manuscript preparation stage because of our negligence. In order to showing the progress of this field more clearly, we decide to add three missed papers by Professor Gustafson to the reference list. We are very sorry for our carelessness. The remarks for adding reference can be found in the attached PDF file.

The final list of missing references:

1. Cox SD, Gustafson JE, Mann CM, Markham JL, Liew YC, Hartland RP, Bell HC, Warmington JR, Wyllie SG (1998). Tea tree oil causes $\mathrm{K}+$ leakage and inhibits respiration in Escherichia coli. Letters in Apllied Microbiology. 26, 355-358.

2. Cuaron JA, Dulal S, Song Y, Singh AK, Montelongo CE, Yu WQ, Nagarajan V, Jayaswal RK, Wilkinson BJ, Gustafson JE (2012). Tea tree oil-induced transcriptional alterations in Staphylococcus aureus. Phytotherapy Research. DOI:10.1002/ptr.4738.

3. Gustafson JE, Liew YC, Chew S, Markham J, Bell HC, Wyllie SG, Warmington JR (1998). Effects of tea tree oil on Escherichia coli. Letters in Applied Microbiology. 26, 194-198.

The online version of the original article can be found at http://dx.doi. org/10.1007/s00253-016-7692-4.

Qing-Shan Shi

jigan@gdim.cn

\footnotetext{
State Key Laboratory of Applied Microbiology Southern China, Guangdong Provincial Key Laboratory of Microbial Culture Collection and Application, Guangdong Institute of Microbiology, Guangzhou 510070, China
} 